\title{
Effects of structured medium- and long-chain triacylglycerols in diets with various levels of fat on body fat accumulation in rats
}

\author{
Tatsuhiro Matsuo ${ }^{1 *}$ and Hiroyuki Takeuchi ${ }^{2}$ \\ ${ }^{1}$ Faculty of Agriculture, Kagawa University, Ikenobe, Kita-gun, Miki-cho, Kagawa 761-0795, Japan \\ ${ }^{2}$ Division of Food Science, Research Laboratory of Nisshin Oillio, Ltd, Yokosuka, Kanagawa 239-0832, Japan
}

(Received 31 March 2003 - Revised 27 August 2003 - Accepted 7 October 2003)

\begin{abstract}
The effects of structured medium- and long-chain triacylglycerols (MLCT) in diets containing 50-200 g fat $/ \mathrm{kg}$ on body fat accumulation were compared with those of long-chain triacylglycerols (LCT) in rats. In rats fed ad libitum, weights of intra-abdominal adipose tissues and carcass fat contents were significantly smaller $(P<0.05)$ in rats fed the $150-200 \mathrm{~g} \mathrm{MLCT} / \mathrm{kg}$ diet than in rats fed $150-200 \mathrm{~g} \mathrm{LCT} / \mathrm{kg}$ diet. Serum and liver triacylglycerol contents were significantly greater $(P<0.05)$ in rats fed $200 \mathrm{~g}$ MLCT/kg diet, as were hepatic capacities of citrate synthase and cytochrome oxidase $(P<0.05)$. The effects of MLCT on body fat were also examined in adult rats fed a limited amount of food (approximately $50 \%$ of ad libitum intake). Reduction of body fat deposition during the food restriction was the same between in LCT and MLCT groups. These results suggest that accumulation of body fat was less efficient during longterm feeding of MLCT than LCT in rats fed high-fat diets ad libitum. The effect of MLCT on body fat might be influenced by the dietary fat content or by energy sufficiency.
\end{abstract}

Body fat accumulation: Structured medium- and long-chain triacylglycerols: Dietary fat: Food restriction: Rats

Obesity is characterized by an increase in lipid stores (Flatt, 1987; Fricker et al. 1989). It is generally associated with enhanced lipid consumption, which contributes to its development. In westernized countries, obesity is an important health problem affecting a large proportion of individuals, many of whom seek to prevent further weight gain or decide to counteract the detrimental health consequences of obesity (Atkinson, 1992). To attain these objectives, patients follow a wide variety of preventive or therapeutic methods, taken alone or in combination. Among these approaches, dietary restriction involving lipids is considered most important. The bulk of fatty acids found in most western diets consist of molecules comprising twelve or more $\mathrm{C}$ atoms. These long-chain fatty acids (LCFA), either saturated or unsaturated, originate from the long-chain triacylglycerols (LCT) provided by vegetable and/or animal oil and fat sources. They contribute to the supply of energy and fulfil essential fatty acid requirements (Bach et al. 1996).

In contrast, medium-chain triacylglyerols (MCT) are edible oils composed of triacylglycerols with saturated medium-chain fatty acids (MCFA) moieties of six to ten $\mathrm{C}$ atoms. These have been introduced into clinical nutrition programmes because of their rapid absorption and solubility (Seaton et al. 1986). MCT are metabolized differently from LCT. They are transported to the liver directly via hepatic portal circulation and are oxidized to ketones, whereas LCT are absorbed via the intestinal lymphatic ducts and transported in chylomicrons through the thoracic duct to reach the systemic circulation (Bach \& Babyan, 1982; Senior 1990).

In animal studies, rats fed MCT do not gain as much weight as rats fed an isoenergetic amount of LCT (Bray et al. 1980; Bach \& Babyan, 1982; Geliebter et al. 1983; Senior, 1990). Fat deposition is diminished, while RMR is increased (Bray et al. 1980; Baba et al. 1982; Geliebter et al. 1983; Senior, 1990). In clinical studies, Seaton et al. (1986) reported that mean postprandial $V_{\mathrm{O}_{2}}$ after a meal containing MCT was higher than after a meal containing LCT. These findings suggest that MCT could be useful in the dietary treatment of obesity. However, it is difficult to substitute MCT for LCT in dietary fat for long-term dietary therapy, in part because utilization of MCT as a cooking oil is limited by the lower smoke point (Matsuo et al. 2001a).

Recently, we developed a new type of cooking oil composed of structured medium- and long-chain triacylglycerols (MLCT) (Matsuo et al. 2001a,b). The MLCT are structured lipids that contain MCFA $(20 \mathrm{~g} / 100 \mathrm{~g}$ total fatty acids) and LCFA $(80 \mathrm{~g} / 100 \mathrm{~g}$ total fatty acids) in the same triacylglycerol. They are made by transesterification of MCT and LCT, and are superior for cooking to physical

\footnotetext{
Abbreviations: LCFA, long-chain fatty acid; LCT, long-chain triacylglycerol; MCFA, medium-chain fatty acid; MCT, medium-chain triglycerol; MLCT, medium- and long-chain triacylglycerol.

* Corresponding author: Dr Tatsuhiro Matsuo, fax +8187891 3021, email matsuo@ag.kagawa-u.ac.jp
} 
mixtures of MCT and LCT, because the smoke point of the former is higher than that of the latter. If MLCT had similar nutritional and physiological characteristics to MCT, MLCT could be used in a special cooking-oil for dietary therapy. We previously reported that energy expenditure was higher after MLCT ingestion (43.1 g) than after LCT ingestion $(42.6 \mathrm{~g})$ in healthy young women (Matsuo et al. $2001 \mathrm{~b}$ ), and that body fat accumulation was lower in rats fed $250 \mathrm{~g} \mathrm{MLCT} / \mathrm{kg}$ diet than in rats fed $250 \mathrm{~g} \mathrm{LCT} / \mathrm{kg}$ diet for 6 weeks (Takeuchi et al. 2001). However, the amount of MLCT in diets that would be optimum for dietary therapy is not clear.

In the present paper, we report the effects of several levels of MLCT in diets on body fat accumulation in growing rats. Moreover, we demonstrate the effects of MLCT on the decrease of body fat in adult rats fed a limited amount of food, because of the likelihood that MLCT might be useful in low-energy diets for obese people.

\section{Methods}

All procedures involving animals were approved by Experimental Animal Care Committee of the Kagawa University.

Expt 1: effect of medium- and long-chain triacylglycerol in diets with various levels of fat on body fat accumulation in rats

Animals and diets. Forty-eight male Wistar rats (3 weeks old) were obtained from Japan SLC, Inc. (Shizuoka, Japan). The rats were fed CE-2 (CLEA Japan, Tokyo, Japan), a commercial rodent diet, and water ad libitum to the age of 4 weeks. The rats were randomly assigned to eight groups. Half of the groups were fed diets containing LCT, and the other half were fed diets containing MLCT. The difference in dietary treatment was the level of dietary fat, as follows: $50,100,150$ and $200 \mathrm{~g} / \mathrm{kg}$. The composition of experimental diets is shown in Table 1. Soyabean oil was used as the source of LCT, and was purchased from Nacalai Tesque, Inc. (Kyoto, Japan). MLCT were prepared

Table 1. Composition of experimental diets $(\mathrm{g} / \mathrm{kg})$

\begin{tabular}{|c|c|c|c|c|}
\hline \multirow[b]{2}{*}{ Ingredients } & \multicolumn{4}{|c|}{ Fat in experimental diets $(\mathrm{g} / \mathrm{kg})$} \\
\hline & 50 & 100 & 150 & 200 \\
\hline Casein & $255 \cdot 0$ & $255 \cdot 0$ & 255.0 & $255 \cdot 0$ \\
\hline DL-Met & 4.0 & $4 \cdot 0$ & 4.0 & 4.0 \\
\hline Maize starch & $460 \cdot 0$ & $410 \cdot 0$ & $360 \cdot 0$ & $310 \cdot 0$ \\
\hline Sucrose & $120 \cdot 0$ & $120 \cdot 0$ & $120 \cdot 0$ & $120 \cdot 0$ \\
\hline $\mathrm{Fat}^{*}$ & $50 \cdot 0$ & $100 \cdot 0$ & $150 \cdot 0$ & $200 \cdot 0$ \\
\hline Cellulose & $50 \cdot 0$ & $50 \cdot 0$ & $50 \cdot 0$ & $50 \cdot 0$ \\
\hline Vitamin mixture $†$ & $13 \cdot 0$ & $13 \cdot 0$ & $13 \cdot 0$ & $13 \cdot 0$ \\
\hline Mineral mixture & $45 \cdot 0$ & $45 \cdot 0$ & $45 \cdot 0$ & $45 \cdot 0$ \\
\hline Choline chloride & 2.5 & 2.5 & 2.5 & 2.5 \\
\hline $\begin{array}{l}\text { Butylated } \\
\text { hydroxytoluene }\end{array}$ & 0.50 & 0.50 & 0.50 & 0.50 \\
\hline Total & $1000 \cdot 0$ & $1000 \cdot 0$ & $1000 \cdot 0$ & $1000 \cdot 0$ \\
\hline
\end{tabular}

*Soyabean oil and structured medium- and long-chain triacylglycerol were used as experimental fats.

† Based on AIN-76A mineral and vitamin mixtures. by transesterification of $200 \mathrm{~g}$ MCT and $800 \mathrm{~g}$ rapeseed oil (Takeuchi et al. 2001), which were purchased from Nisshin Oil Mills (Tokyo, Japan). Composition of fatty acids and triacylglycerols of the test oils have been described previously (Matsuo et al. 2001b): LCT contained (g/100 g total fatty acids): linoleic acid 53, oleic acid 24, $\alpha$-linolenic acid 8; MLCT contained (g/100 g total fatty acids): oleic acid 50, linoleic acid 16, caprylic acid 14, capric acid 5.

Experimental design. The animals were individually housed in an animal room at $24 \pm 1{ }^{\circ} \mathrm{C}$ with lights on from 08.00 to 20.00 hours. Each group of rats was given free access to experimental diet and water for 8 weeks. Body weights and food intakes were monitored daily. On the final day, rats in each dietary group were fasted for $12 \mathrm{~h}$ from 22.00 hours, then killed by decapitation. Blood was collected to obtain serum; liver and intra-abdominal adipose tissues (epididymal, perirenal and mesenteric) were quickly removed, weighed, and stored at $-40^{\circ} \mathrm{C}$ until analyses. Carcass samples were obtained by removing the head, tail and splanchnic tissues, and were stored at $-20^{\circ} \mathrm{C}$ until analysis of carcass composition.

Analysis. Concentrations of serum glucose and triacylglycerols were determined by methods reported previously (Fletcher, 1968; Bergmeyer \& Bent, 1974). Serum insulin concentration was determined by a rat insulin enzyme immunoassay system purchased from Amersham Biosciences Inc. (Tokyo, Japan). Liver total lipid was extracted by the method of Folch et al. (1957) and liver triacylglycerol was measured by the method of Fletcher (1968). Carcass fat and protein were analysed using the method reported by Mickelsen \& Anderson, (1959). For assays of hepatic capacities of citrate synthase and cytochrome oxidase, the frozen tissues were homogenized at $0-4^{\circ} \mathrm{C}$ in $0 \cdot 1 \mathrm{M}$-phosphate buffer ( $\mathrm{pH} 7.5$ ) containing Triton X-100 $(10 \mathrm{~g} / \mathrm{l})$ with three $20 \mathrm{~s}$ bursts of a motor-driven homogenizer (Ultra-Turrax T8; IKA Labortechnik, Staufen, Germany). Tissue capacity of the cytochrome oxidase was measured by the method of Smith (1955) using the homogenate. The rest of the homogenate was centrifuged at $0-4^{\circ} \mathrm{C}$ for $15 \mathrm{~min}$ at $600 \mathrm{~g}$. The supernatant fraction was used for measuring hepatic capacity of the citrate synthase by the method described by Srere (1969). The hepatic capacity of the enzymes were measured at $25^{\circ} \mathrm{C}$ and expressed as units per $\mathrm{g}$ wet weight. One unit of the enzyme catalysed the formation of $1 \mu \mathrm{mol}$ free $\mathrm{CoA} / \mathrm{min}$ for citrate synthase, and $1 \mu \mathrm{mol}$ oxidized cytochrome $\mathrm{cl}$ min for cytochrome oxidase.

\section{Expt 2: effect of medium- and long-chain triacylglycerol in diets with various levels of fat in rats fed a limited amount of food for weight reduction}

Animals and experimental design. Fifty-four male Wistar rats (10 weeks old) were obtained from Japan SLC, Inc. The rats were fed CE-2 diet (CLEA Japan) and water $a d$ libitum, to the age of 15 weeks. After the pre-feeding period, six rats were killed as a control before initiation of food restriction, and each factor described later was analysed. The rest of the rats were randomly divided into eight groups. Half of the groups were fed diets containing LCT, and the other half were fed diets containing MLCT. 
The difference in dietary treatment was the level of dietary fat as described in Expt 1. Diet composition and housing conditions were the same as in Expt 1. Each group of rats was fed $6 \mathrm{~g} \mathrm{diet/d} \mathrm{(approximately} 50 \%$ of the meal observed in Expt 1) for weight reduction. The food restriction regimen was carried out for $21 \mathrm{~d}$. On the final day of the experiment, rats in each group were killed by decapitation at 10.00 hours. Blood, organs, and carcass samples were collected and stored as described in Expt 1.

Analysis. Serum components, liver triacylglycerol, carcass compositions and enzyme capacities were assayed as in Expt 1.

\section{Data analysis}

All data were analysed by a factorial ANOVA and post hoc Scheffé's test. Differences were considered statistically significant at $P<0.05$.

\section{Results}

Expt 1

Body weight, food intake and food efficiency. In the LCT groups, final body weight and weight gain were significantly lower $(P<0.05)$ in rats fed 50 and $100 \mathrm{~g}$ fat $/ \mathrm{kg}$ diet than in rats fed 150 and $200 \mathrm{~g}$ fat $/ \mathrm{kg}$ diet (Table 2). In the 150 and $200 \mathrm{~g}$ fat $/ \mathrm{kg}$ diets groups, final body weight and weight gain were significantly lower $(P<0.05)$ in the MLCT groups than in the LCT groups (Table 2). Food intake was more suppressed by the feeding of a high-fat diet, and food efficiency increased significantly $(P<0.05)$ with increasing dietary fat both in the LCT and MLCT groups (Table 2). In the 150 and $200 \mathrm{~g}$ fat $/ \mathrm{kg}$ diet groups, food efficiency was significantly lower $(P<0.05)$ in the MLCT groups (Table 2$)$.
Tissue weights and liver triacylglycerol. Liver weight and triacylglycerol content were not influenced by the levels of LCT and MLCT (Table 3). In the $200 \mathrm{~g}$ fat $/ \mathrm{kg}$ diet group, liver triacylglycerol content was significantly higher $(P<0.05)$ in rats fed MLCT diets than in rats fed LCT diets (Table 3 ). Weights of intra-abdominal adipose tissues increased with increasing dietary fat in the LCT group (Table 3 ). In the 150 and $200 \mathrm{~g}$ fat $/ \mathrm{kg}$ diet groups, perirenal adipose tissue weight and total intra-abdominal adipose tissue weight were significantly lower $(P<0.05)$ in rats fed MLCT diets than in rats fed LCT diets (Table 3).

Carcass fat and protein. Carcass weight and carcass fat content increased with increasing dietary fat in the LCT group (Table 4). In the 150 and $200 \mathrm{fat} / \mathrm{kg}$ diet groups, carcass weight and carcass fat content were significantly lower $(P<0.05)$ in rats fed MLCT diets than in rats fed LCT diets (Table 4). Carcass protein content was not affected by dietary fat level or dietary fatty acid composition (Table 4).

Relationship between fat intake and body fat deposition. Intra-abdominal adipose tissues and carcass fat content were positively correlated with LCT intake (epididymal $r$ 0.677, $P<0.001$; perirenal $r 0.679, P<0.001$; mesenteric $r 0.582, P<0.01$; carcass fat $r 0.487, P<0.05$ ), but were not correlated with MLCT intake (epididymal $r$ 0.204, $P=0.34$; perirenal $r 0.18, P=0.40$; mesenteric $r 0.326$, $P=0.12$; carcass fat $r 0.044, P=0 \cdot 84)$. Liver triacylglycerol content was not correlated with LCT or MLCT intake.

Serum glucose, insulin and triacylglycerol concentrations. Serum glucose and insulin concentrations were significantly lower $(P<0.05)$ in the $50 \mathrm{~g}$ fat $/ \mathrm{kg}$ diet group than in 100,150 , and $200 \mathrm{~g}$ fat $/ \mathrm{kg}$ diet groups in rats fed LCT and MLCT diets (Table 5). In the $200 \mathrm{~g}$ dietary fat $/ \mathrm{kg}$ diet group, serum triacylglycerol concentration was significantly higher $(P<0.05)$ in rats fed MLCT diet than in rats fed LCT (Table 5).

Table 2. Body weight, food intake and food efficiency in rats fed experimental diets (Exp 1)† (Mean values with their standard errors for six rate per group)

\begin{tabular}{|c|c|c|c|c|c|c|c|c|c|}
\hline & & \multicolumn{8}{|c|}{ Fat in experimental diets $(\mathrm{g} / \mathrm{kg})$} \\
\hline & & \multicolumn{2}{|c|}{50} & \multicolumn{2}{|c|}{100} & \multicolumn{2}{|c|}{150} & \multicolumn{2}{|c|}{200} \\
\hline & & Mean & SEM & Mean & SEM & Mean & SEM & Mean & SEM \\
\hline \multicolumn{10}{|c|}{ Body weight (g) } \\
\hline \multirow[t]{2}{*}{ Initial } & $L^{131}$ & 87 & 2 & 88 & 1 & 88 & 1 & 89 & 1 \\
\hline & $\mathrm{ML}$ & 88 & 1 & 88 & 1 & 88 & 1 & 88 & 1 \\
\hline \multirow{2}{*}{ Final } & $\mathrm{L}$ & $273^{b}$ & 9 & $275^{\mathrm{b}}$ & 5 & $293^{a}$ & 5 & $297^{a}$ & 6 \\
\hline & $\mathrm{ML}$ & 272 & 7 & 272 & 8 & $272^{*}$ & 6 & $278^{*}$ & 6 \\
\hline \multirow[t]{2}{*}{ Gain } & $\mathrm{L}$ & $186^{\mathrm{b}}$ & 8 & $187^{\mathrm{b}}$ & 5 & $205^{a}$ & 5 & $208^{a}$ & 5 \\
\hline & ML & 185 & 7 & 185 & 7 & $184^{*}$ & 5 & $190^{\star}$ & 6 \\
\hline \multicolumn{10}{|c|}{ Food intake $(\mathrm{g})$} \\
\hline & $L^{\prime \prime}$ & $14 \cdot 3^{a}$ & 0.4 & $13 \cdot 7^{\mathrm{ab}}$ & 0.2 & $13 \cdot 6^{\mathrm{ab}}$ & 0.2 & $13 \cdot 1^{b}$ & 0.2 \\
\hline & $\mathrm{ML}$ & $14 \cdot 7^{a}$ & 0.3 & $13 \cdot 8^{\mathrm{ab}}$ & 0.4 & $12 \cdot 9^{\mathrm{b}}$ & 0.4 & $12 \cdot 5^{\mathrm{b}}$ & 0.4 \\
\hline \multicolumn{10}{|c|}{ Food efficiency $(\mathrm{mg} / \mathrm{g})$} \\
\hline & L & $236^{d}$ & 4 & $248^{c}$ & 3 & $274^{\mathrm{b}}$ & 4 & $289^{a}$ & 4 \\
\hline & $\mathrm{ML}$ & $229^{d}$ & 4 & $245^{c}$ & 4 & $259^{\mathrm{bc}}$ & 3 & $276^{a b}$ & 8 \\
\hline
\end{tabular}

$\mathrm{L}$, soyabean-oil diet; ML, structured medium- and long-chain triacylgrlycerol diet.

a,b,c,d Mean values within a row with unlike superscript letters were significantly different $(P<0.05)$. Mean values were significantly different from those of the $L$ group: ${ }^{\star} P<0.05$.

†For details of diets and procedures, see Table 1 and p. 220. 
Table 3. Liver weight, liver triacylglycerol weight and intra-abdominal adipose tissue weights in rats fed experimental diets (Exp 1)†

(Mean values with their standard errors for six rate per group)

\begin{tabular}{|c|c|c|c|c|c|c|c|c|}
\hline & \multicolumn{8}{|c|}{ Fat in experimental diets $(\mathrm{g} / \mathrm{kg})$} \\
\hline & \multicolumn{2}{|c|}{50} & \multicolumn{2}{|c|}{100} & \multicolumn{2}{|c|}{150} & \multicolumn{2}{|c|}{200} \\
\hline & Mean & SEM & Mean & SEM & Mean & SEM & Mean & SEM \\
\hline \multicolumn{9}{|c|}{ Liver weight (q) } \\
\hline $\mathrm{L}$ & $11 \cdot 2$ & 0.5 & 11.1 & 0.4 & $11 \cdot 7$ & 0.2 & 11.8 & 0.4 \\
\hline ML & $11 \cdot 3$ & 0.4 & 11.8 & 0.4 & 11.8 & 0.3 & $11 \cdot 7$ & 0.6 \\
\hline \multicolumn{9}{|c|}{ Liver triacylglycerol (mg/g) } \\
\hline L & $20 \cdot 8$ & 3.0 & 21.5 & $2 \cdot 2$ & 24.9 & 1.4 & $24 \cdot 6$ & 1.6 \\
\hline$\overline{M L}$ & $25 \cdot 4$ & $2 \cdot 6$ & $27 \cdot 3$ & 1.2 & $28 \cdot 6$ & $1 \cdot 7$ & $30 \cdot 8^{*}$ & 3.1 \\
\hline \multicolumn{9}{|c|}{ Epididymal adipose tissue (g) } \\
\hline L & $7 \cdot 0^{\mathrm{b}}$ & 0.2 & $8 \cdot 2^{a}$ & 0.2 & $8 \cdot 6^{a}$ & 0.4 & $8 \cdot 8^{\mathrm{a}}$ & 0.4 \\
\hline ML & $8 \cdot 1$ & 0.3 & $8 \cdot 0$ & 0.4 & $7 \cdot 7$ & 0.2 & 7.5 & 0.5 \\
\hline \multicolumn{9}{|c|}{ Perirenal adipose tissue (g) } \\
\hline $\mathrm{L}$ & $7 \cdot 6^{\mathrm{b}}$ & 0.2 & $8 \cdot 0^{\mathrm{b}}$ & 0.2 & $9 \cdot 1^{\mathrm{a}}$ & 0.2 & $8.9^{a}$ & 0.3 \\
\hline $\mathrm{ML}$ & 7.9 & 0.5 & $8 \cdot 3$ & 0.3 & $7 \cdot 8^{\star}$ & 0.2 & $7 \cdot 5^{\star}$ & 0.4 \\
\hline \multicolumn{9}{|c|}{ Mesenteric adipose tissue $(\mathrm{g})$} \\
\hline L & $5 \cdot 8^{\mathrm{b}}$ & 0.3 & $6 \cdot 0^{\mathrm{a}}$ & 0.2 & $6 \cdot 8^{\mathrm{a}}$ & 0.3 & $6 \cdot 9^{\mathrm{a}}$ & 0.4 \\
\hline $\mathrm{ML}$ & $6 \cdot 6$ & 0.4 & $6 \cdot 1$ & 0.3 & $5 \cdot 8$ & 0.4 & $5 \cdot 7^{*}$ & 0.3 \\
\hline \multicolumn{9}{|c|}{ Total intra-abdominal adipose tissue $(\mathrm{g})$} \\
\hline L & $20 \cdot 4^{\mathrm{c}}$ & 0.7 & $22 \cdot 2^{b}$ & 0.2 & $24 \cdot 5^{a}$ & 0.7 & $24 \cdot 6^{\mathrm{a}}$ & 0.9 \\
\hline $\mathrm{ML}$ & $22 \cdot 6$ & 1.2 & 22.4 & 0.9 & $21 \cdot 3^{*}$ & 0.9 & $20 \cdot 7^{\star}$ & 1.0 \\
\hline
\end{tabular}

$\mathrm{L}$, soyabean-oil diet; ML, structured medium- and long-chain triacylglycerol diet.

$a, b, c$ Mean values within a row with unlike superscript letters were significantly different $(P<0.05)$.

Mean values were significantly different from those of the $L$ group: ${ }^{\star} P<0.05$.

†For details of diets and procedures, see Table 1 and p. 220

Hepatic capacity of the enzymes. Hepatic capacities of the citrate synthase and cytochrome oxidase were not influenced by level of LCT, but were increased by increased MLCT in diets (Fig. 1). In the 150 and $200 \mathrm{~g}$ fat $/ \mathrm{kg}$ diet groups, hepatic capacities of the citrate synthase and cytochrome oxidase were significantly higher $(P<0.05)$ in rats fed MLCT than in rats fed LCT (Fig. 1).
Expt 2

Body weight. Rat body-weights reached approximately 280 (range 282-286) g before initiation of the food-restriction regimen. Food restriction for $21 \mathrm{~d}$ resulted in a loss of body weight to $223-240 \mathrm{~g}$ in all the groups, and the resulting body weights of rats fed both LCT and MLCT were the same. Total loss of body weight was less as both LCT and

Table 4. Carcass composition in rats fed experimental diets (Exp 1)† (Mean values with their standard errors for six rats per group)

\begin{tabular}{|c|c|c|c|c|c|c|c|c|}
\hline & \multicolumn{8}{|c|}{ Fat in experimental diets $(\mathrm{g} / \mathrm{kg})$} \\
\hline & \multicolumn{2}{|c|}{50} & \multicolumn{2}{|c|}{100} & \multicolumn{2}{|c|}{150} & \multicolumn{2}{|c|}{200} \\
\hline & Mean & SEM & Mean & SEM & Mean & SEM & Mean & SEM \\
\hline \multicolumn{9}{|c|}{ Carcass weight (g) } \\
\hline $\mathrm{L}$ & $164^{b}$ & 4 & $160^{\mathrm{b}}$ & 2 & $180^{\mathrm{a}}$ & 4 & $181^{\mathrm{a}}$ & 3 \\
\hline ML & 161 & 4 & 163 & 3 & $160^{*}$ & 5 & $165^{\star}$ & 1 \\
\hline \multicolumn{9}{|c|}{ Carcass fat $(\mathrm{g})$} \\
\hline L & $36.7^{b}$ & 1.9 & $37 \cdot 3^{\mathrm{b}}$ & 1.9 & $43 \cdot 6^{\mathrm{a}}$ & 2.4 & $43 \cdot 2^{a}$ & 2.9 \\
\hline ML & $36 \cdot 8$ & $1 \cdot 7$ & $37 \cdot 1$ & $1 \cdot 1$ & $35 \cdot 7^{\star}$ & $1 \cdot 8$ & $36 \cdot 5^{\star}$ & 1.5 \\
\hline \multicolumn{9}{|c|}{ Carcass fat (\%) } \\
\hline L & 22.4 & 1.3 & $23 \cdot 3$ & 1.3 & 24.2 & 0.9 & $23 \cdot 8$ & 1.5 \\
\hline \multirow{2}{*}{\multicolumn{9}{|c|}{ Carcass protein $(\mathrm{g})$}} \\
\hline & & & & & & & & \\
\hline $\mathrm{L}$ & 38.0 & $2 \cdot 1$ & $35 \cdot 8$ & 1.5 & $40 \cdot 3$ & 1.2 & $39 \cdot 0$ & 1.5 \\
\hline $\mathrm{ML}$ & 39.3 & 1.6 & $37 \cdot 8$ & 1.2 & $40 \cdot 0$ & $1 . \overline{5}$ & 38.5 & 1.4 \\
\hline \multicolumn{9}{|c|}{ Carcass protein $(\%)$} \\
\hline L & $23 \cdot 1$ & 0.9 & $22 \cdot 4$ & $1 \cdot 1$ & $22 \cdot 4$ & 0.4 & $21 \cdot 6$ & 0.8 \\
\hline $\mathrm{ML}$ & 24.4 & 0.5 & $23 \cdot 2$ & 0.4 & $24.9^{*}$ & 0.3 & $24 \cdot 1^{*}$ & 0.9 \\
\hline
\end{tabular}

L, soyabean-oil diet; ML, structured medium- and long-chain triacylglycerol diet.

a,b Mean values within a row with unlike superscript letters were significantly different $(P<0.05)$

Mean values were significantly different from those of the $L$ group: ${ }^{\star} P<0.05$.

†For details of diets and procedures, see Table 1 and $p .220$. 
Table 5. Serum glucose, insulin and triacylglycerol concentrations in rats fed experimental diets (Exp 1)† (Mean values with their standard errors for six rats per group)

\begin{tabular}{|c|c|c|c|c|c|c|c|c|}
\hline & \multicolumn{8}{|c|}{ Fat in experimental diets $(\mathrm{g} / \mathrm{kg})$} \\
\hline & \multicolumn{2}{|c|}{50} & \multicolumn{2}{|c|}{100} & \multicolumn{2}{|c|}{150} & \multicolumn{2}{|c|}{200} \\
\hline & Mean & SEM & Mean & SEM & Mean & SEM & Mean & SEM \\
\hline \multicolumn{9}{|c|}{ Glucose $(\mathrm{mg} / \mathrm{ml})$} \\
\hline L & $1.69^{b}$ & 0.04 & $1.80^{\mathrm{a}}$ & 0.05 & $1.86^{\mathrm{a}}$ & 0.05 & $1.85^{\mathrm{a}}$ & 0.05 \\
\hline ML & $1.73^{\mathrm{b}}$ & 0.08 & $1.94^{\mathrm{a}}$ & 0.07 & $1.90^{\mathrm{a}}$ & 0.03 & $1.97^{\mathrm{a}}$ & 0.10 \\
\hline \multicolumn{9}{|c|}{ Insulin (ng/ml) } \\
\hline L & $73.1^{b}$ & 0.6 & $77 \cdot 5^{a}$ & 1.0 & $78 \cdot 4^{a}$ & 1.5 & $77 \cdot 7^{\mathrm{a}}$ & 0.9 \\
\hline ML & $74 \cdot 4^{b}$ & 0.7 & $77 \cdot 8^{\mathrm{a}}$ & $1 \cdot 1$ & $79 \cdot 2^{\mathrm{a}}$ & $1 \cdot 2$ & $78 \cdot 1^{a}$ & 1.9 \\
\hline \multicolumn{9}{|c|}{ Triacylglycerol (mg/ml) } \\
\hline $\mathrm{L}$ & 1.87 & 0.17 & 2.04 & 0.36 & 1.93 & 0.15 & 1.55 & 0.22 \\
\hline ML & $2 \cdot 16$ & 0.30 & 2.40 & 0.30 & $2 \cdot 17$ & 0.25 & $2 \cdot 52^{\star}$ & 0.40 \\
\hline
\end{tabular}

MLCT were increased in diets (mean values 57, 55, 48 and $46 \mathrm{~g}$ for $50,100,150$ and $200 \mathrm{~g}$ fat $/ \mathrm{kg}$ diet groups respectively).

Tissue weights and liver triacylglycerol. The weights of liver, epididymal, perirenal and mesenteric adipose tissues reached $10 \cdot 8,6 \cdot 2,5.4$ and $4.4 \mathrm{~g}$ respectively before initiation of the food-restriction regimen. All of the weights of liver and adipose tissues were decreased by the food restriction (weight loss (\%): liver 43-48, epididymal fat $35-60$, perirenal fat 55-80, mesenteric fat 52-82). Liver triacylglycerol and weights of intra-abdominal adipose tissues had increased with increase in both LCT and MLCT in diets, but the differences were not observed between in the LCT and MLCT groups.

Carcass fat and protein. Carcass fat and protein content were 25.3 and $48.0 \mathrm{~g}$ respectively before initiation of the food-restriction regimen. On food restriction, the decrease in carcass fat was less as the dietary fat content increased, for both LCT and MLCT diets (mean values $17 \cdot 0,15 \cdot 2,13.1$ and $12.6 \mathrm{~g}$ for $50,100,150$ and $200 \mathrm{~g}$ fat $/ \mathrm{kg}$ groups, respectively). There was no difference between LCT and MLCT groups. Carcass protein content and decrease in carcass protein were not influenced by dietary fat content or fatty acid composition (range of mean values $(\mathrm{g})$ : carcass protein $38.6-41.5$, decrease in carcass protein $6 \cdot 5-9 \cdot 4)$.

Serum glucose, insulin and triacylglycerol concentrations. Serum triacylglycerol concentration was dramatically decreased by food restriction (mean values $(\mathrm{mg} / \mathrm{ml})$ : control group $2 \cdot 25$, restrictive-diet groups $0.53-0.74)$. The concentrations of serum glucose, insulin and triacylglycerol were not affected by dietary fat content or fatty acid composition (range of mean values $(\mathrm{mg} / \mathrm{ml})$ : serum glucose $1.51-1.73$, serum insulin 69.6-77.1).

Hepatic capacity of the enzymes. Hepatic activities of citrate synthase and cytochrome oxidase were not influenced by dietary fat content or fatty acid composition (range of mean values (U/g): citrate synthase 29.2-32.8, cytochrome oxidase $46 \cdot 7-51 \cdot 2$.

\section{Discussion}

Many studies have reported that body fat accumulation is lower in animals fed MCT $v$. LCT diets (Bray et al. 1980; Bach \& Babyan, 1982; Geliebter et al. 1983; Senior, 1990). However, the effect of dietary MLCT on body fat accumulation is unclear. Moreover, the effects of dietary MLCT level or food restriction on rat body fat deposition have not been examined. The present study was undertaken to investigate the effect of several level of MLCT in diets on body fat accumulation under growth and food restriction conditions. We have shown here that body fat accumulation was less in rats fed MLCT diets than in rats fed high-fat $(150-200 \mathrm{~g}$ fat $/ \mathrm{kg})$ LCT diets (Expt 1). Moreover, intraabdominal adipose tissues and carcass fat content were positively correlated with LCT intake, but not with MLCT intake (Expt 1). On the other hand, reduction of body fat deposition during the food restriction was the same between in LCT and MLCT groups (Expt 2). These results suggest that the MLCT diet would effectively inhibit body fat deposition in rats with high-fat feeding under energy sufficiency. These findings are consistent with the results of our previous report, in which body fat accumulation was greater in rats fed high-LCT diets $(250 \mathrm{~g} / \mathrm{kg}) v$. rats fed high-MLCT diets for 6 weeks (Takeuchi et al. 2001). The present study also supports our clinical reports concerning MLCT (Matsuo et al. 2001a) and MCT (Tsuji et al. 2001).

MCT and LCT have different metabolic fates, which may account for the difference in postprandial thermogenesis. MCT are rapidly absorbed in the small intestine and transported to the liver as NEFA via hepatic portal circulation (Hashim \& Tantibhedyangkul, 1987; Linscheer et al. 1970; Odle et al. 1991). MCFA enter the mitochondria of liver cells independently of fatty acyl-CoA-carnitine transferase, which is necessary for the transport of LCFA into mitochondria (Senior, 1990; Papamandjaris et al. 1998). Acetyl-CoA formed by $\beta$-oxidation can be oxidized further via the Krebs cycle to $\mathrm{CO}_{2}$ and water. In the present study, hepatic capacities of the citrate synthase and cytochrome oxidase, key enzymes in the mitochondrial Krebs cycle 

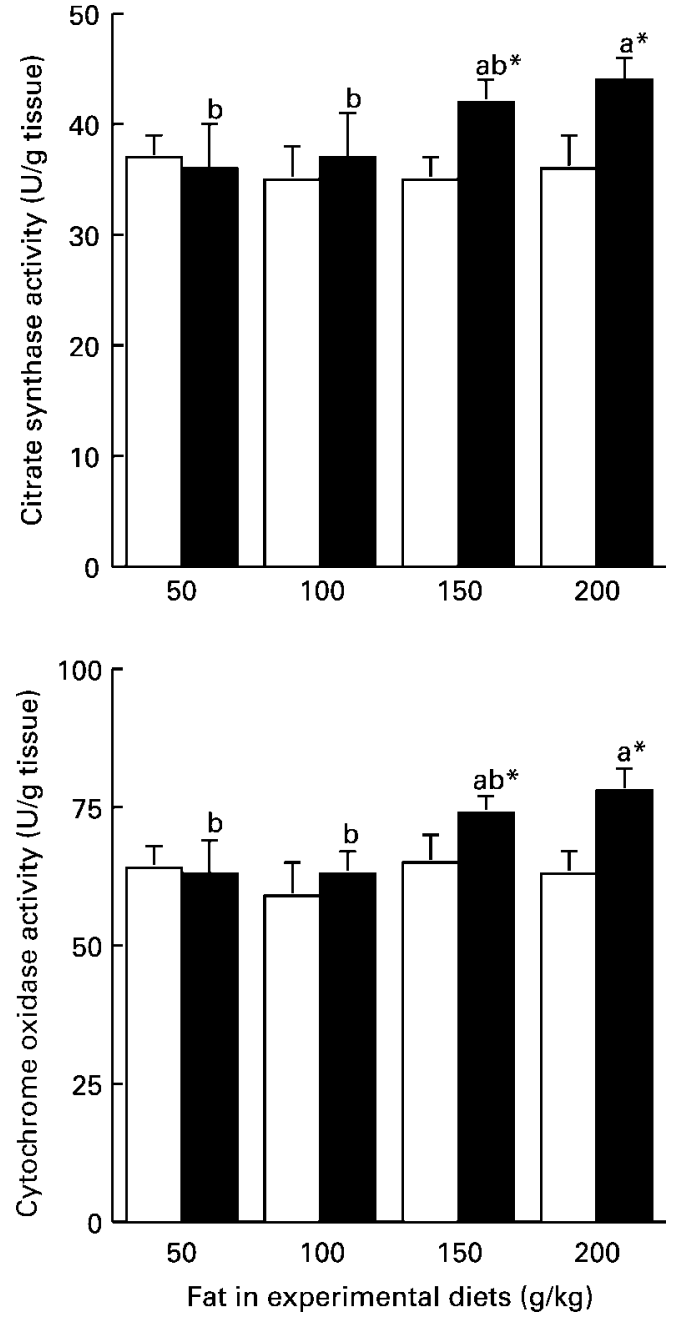

Fig. 1. Hepatic activities of the oxidative enzymes in rats fed experimental diets containing various levels of long-chain triacylglycerols (LCT, $\square$ ) or medium- and long-chain triaclyglycerols (MLCT, 口) (Expt 1). One unit $(U)$ of the enzyme catalysed the formation of $1 \mu \mathrm{mol}$ free $\mathrm{CoA} / \mathrm{min}$ for citrate synthase or $1 \mu \mathrm{mol}$ oxidized cytochrome $\mathrm{c} / \mathrm{min}$ for cytochrome oxidase. Values are means with their standards errors shown by vertical bars (six rats per group). For details of diets and procedures, see Table 1 and p. 220. ${ }^{a, b}$ Mean values within the MLCT groups with unlike superscript letters were significantly different $(P<0.05)$. Mean values were significantly different from the those of the LCT group: ${ }^{*} P<0.05$.

and electron transport chain, are used as markers for mitochondrial oxidative capacity. The capacities of these enzymes were higher in rats fed 150-200 g MLCT/kg diets under ad libitum conditions. These findings suggest that the higher capacity for mitochondrial oxidation might be related to the mechanism of lower body fat accumulation induced by the greater thermic effects of MLCT (Seydoux et al. 1986; Surette et al. 1992). The increase in thermogenesis following MLCT ingestion suggests that the liver may play an important role in postprandial thermogenesis, as proposed previously (Ruderman \& Goodman, 1973; Berry et al. 1986; Bach et al. 1996). Several hypothetical mechanisms may be propounded to explain the increased thermic effect of MLCT: a specific regulatory thermogenesis dependent on peroxizomal $\beta$-oxidation in brown adipose tissue (Rothwell \& Stock, 1987); a partial uncoupling of oxidative phosphroylation (Baba et al. 1987); a retroconversion of some ATP molecules produced during the accelerated oxidation of MCFA to ADP to restore a normal ATP:ADP ratio (Johnson \& Cotter, 1986). Another possibility is that heat is produced in the liver induced by uncoupling protein-2 (Ricquier \& Bouilla, 1998; ViguerieBascand et al. 1999).

In the present study, serum triacylglycerol levels and liver triacylglycerol contents were significantly greater in rats fed $200 \mathrm{~g} \mathrm{MLCT} / \mathrm{kg}$ diet than in rats fed $200 \mathrm{~g} \mathrm{LCT/}$ $\mathrm{kg}$ diet under the ad libitum feeding conditions (Expt 1). Excess acetyl-CoA produced by $\beta$-oxidation of MCFA, and not oxidized in liver mitochondria, was used in the synthesis of LCFA (Senior, 1990; Papamandjaris et al. 1998). Hill et al. $(1989,1990)$ reported that $6 \mathrm{~d}$ of overfeeding with MCT significantly increased blood triacylglycerol concentration compared with LCT in non-obese male subjects. They suggested that changes in blood lipids with MCT feeding are consist with the hypothesis that excess dietary MCT causes a significant increase in the hepatic synthesis and/or chain elongation and desaturation. These processes could account for the higher rate of postprandial thermogenesis with MCT as compared with LCT (Hill et al. 1989, 1990). These results are supported by our present findings.

2-Monoacylglycerols released in the intestinal lumen are reconverted to triacylglycerols via the monoacylglycerol pathway, which could make the MCFA included in 2-monoacylglycerols less available for absorption via the portal vein (Ikeda et al. 1991; Christensen et al. 1995). However, medium-chain 2-monoacylglycerols are absorbed much less through lymph than long-chain 2-monoacylglycerols (Ikeda et al. 1991). Since a large proportion of 2-monoacylglycerols is expected to be hydrolysed to MCFA and glycerols by mucosal lipase (Hashim \& Tantibhedyangkul, 1987), production of chylomicron from medium-chain 2-monoacylglycerols may be limited.

MLCT are better for cooking than MCT because of their higher smoke point, which allows the use of larger amounts in cooking oil. In the present study, we demonstrated that body fat accumulation was greater in rats fed LCT diets than in rats fed MLCT diets under the high-fat conditions. However, reduction of body fat content during food restriction was the same in LCT and MLCT groups. It is not entirely clear that the effects of MCLT are retained when this oil is used in cooking regular meals or for long-term diets. Further clinical studies are needed to clarify the impact of MLCT ingestion on human body fat during free-living and dietary therapy.

In summary, effects of MLCT in 50-200 $\mathrm{g}$ fat $/ \mathrm{kg}$ diets on body fat accumulation were compared with those of LCT in rats. In rats fed ad libitum, weights of intraabdominal adipose tissues and carcass fat content were significantly greater in rats fed the 150-200 g MLCT/kg diet. Reduction of body fat content during the food restriction (approximately 50\%) was the same in LCT and MLCT groups. These results suggest that accumulation of body fat was less efficient on long-term feeding of MLCT than on LCT in rats fed high-fat diets ad libitum. The effect of MLCT on body fat might be influenced by $\%$ dietary fat or energy sufficiency. 


\section{References}

Atkinson RL (1992) Treatment of obesity. Nutr Rev 50, 338-354.

Baba N, Bracco EF \& Hashim SA (1982) Enhanced thermogenesis and diminished deposition of fat in response to overfeeding with a diet containing medium chain triglycerides. Am J Clin Nutr 35, 682-687.

Baba N, Bracco EF \& Hashim SA (1987) Role of brown adipose tissue in thermogenesis induced by overfeeding a diet containing medium chain triglyceride. Lipids 22, 442-444.

Bach AC \& Babyan UK (1982) Medium-chain triglycerides: an update. Am J Clin Nutr 36, 950-962.

Bach AC, Ingenbleek Y \& Frey A (1996) The usefulness of dietary medium-chain triglycerides in body weight control: fact or fancy? J Lipid Res 37, 708-726.

Bergmeyer HU \& Bent E (1974) D-Glucose: Determination with glucose oxidase and peroxidase. In Methods of Enzymatic Analysis, Vol.3, pp. 1205-1215 [HU Bergmeyer, editor]. New York: Academic Press.

Berry MN, Cleark DG \& Grivell AR (1986) The contribution of hepatic metabolism to diet-induced thermogenesis. Metabolism 24, 141-147.

Bray GA, Lee M \& Bray TL (1980) Weight gain of rats fed medium-chain triglycerides is less than rats fed long-chain triglycerides. Int J Obes 4, 27-32.

Christensen MS, Hoy C, Becker CC \& Redgrave T (1995) Intestinal absorption and lymphatic transport of eicosapentaenoic (EPA), docosahexaenoic (DHA), and decanoic acids: dependence on intramolecular triacylglycerol structure. Am J Clin Nutr 61, 56-61.

Flatt JP (1987) The difference in storage capacities for carbohydrate and for fat, and its implications in the regulation of body weight. Ann NY Acad Sci 49, 104-123.

Fletcher MJ (1968) A colorimetric method for estimation serum triglycerides. Clin Chim Acta 22, 393-397.

Folch J, Lees M \& Sloane-Stanley GH (1957) A simple method for the isolation and purification of total lipides from animal tissues. J Biol Chem 226, 497-509.

Fricker J, Fumeron F, Clair D, et al. (1989) A positive correlation between energy intake and body mass index in a population of 1312 overweight subjects. Int J Obes 13, 663-681.

Geliebter A, Torboy N, Bracco FE, et al. (1983) Overfeeding with medium-chain triglycerides diet results in diminished deposition of fat. Am J Clin Nutr 37, 1-4.

Hashim SA, Krell K \& Mao P (1965) Portal venous transport of free pelargenic acid following intestinal instillation of tripelargonin. Nature 207, 527.

Hashim AS \& Tantibhedyangkul P (1987) Medium chain triglyceride in early life: effects on growth of adipose tissue. Lipids 22, 429-434.

Hill JO, Peters JC, Sharp T, et al. (1989) Thermogenesis in humans during overfeeding with medium-chain triglycerides. Metabolism 38, 641-648.

Hill JO, Peters JC, Swift LL, et al. (1990) Changes in blood lipids during six days of overfeeding with medium or long chain triglycerides. J Lipid Res 31, 407-416.

Ikeda I, Tomari Y, Sugano M, et al. (1991) Lymphatic absorption of structured glycerolipids containing medium-chain fatty acids and linoleic acid, and their effect on cholesterol absorption in rats. Lipids 26, 369-373.
Johnson RC \& Cotter R (1986) Metabolism of medium-chain triglyceride lipid emulsion. Nutrition 2, 150-158.

Linscheer WG, Blum AL \& Platt RR (1970) Transfer of medium chain fatty acids from blood to spinal fluid in patients with cirrhosis. Gastroenterology 58, 509-515.

Matsuo T, Matsuo M, Kasai M, et al. (2001a) Effects of a liquid diet supplement containing structured medium- and long-chain triacylglycerols on body fat accumulation in healthy young subjects. Asia Pac J Clin Nutr 10, 46-50.

Matsuo T, Matsuo M, Taguchi N, et al. (2001b) The thermic effect is greater forstructured medium- and long-chain triacylglycerols versus long-chain triacylglycerols in healthy young women. Metabolism 50, 125-130.

Mickelsen O \& Anderson AA (1959) A method for preparing intact animals for carcass analysis. J Lab Clin Med 53, 282-290.

Odle J, Benevenga NJ \& Crenshaw TD (1991) Utilization of medium-chain triglycerides by neonatal piglets: chain length of even and odd-carbon fatty acids and apparent digestion/absorption and hepatic metabolism. J Nutr 121, 605-614.

Papamandjaris AA, Macdougall DE \& Jones PJH (1998) Medium chain fatty acid metabolism and energy expenditure: obesity treatment implications. Life Sci 62, 1203-1215.

Ricquier D \& Bouilla F (1998) The uncoupling protein homologues: UCP1, UCP2, UCP3, StUCP and AtUCP. Biochem $J$ 345, $161-179$.

Rothwell NJ \& Stock MJ (1987) Stimulation of thermogenesis and brown fat activity in rats fed medium chain triglyceride. Metabolism 36, 128-130.

Ruderman N \& Goodman MN (1973) Regulation of ketone body metabolism in skeletalmuscle. Am J Physiol 224, 1391-1397.

Seaton TB, Well ST, Warenko MK, et al. (1986) Thermic effect of medium-chain and long-chain triglycerides in man. Am J Clin Nutr 44, 630-634.

Senior AR (1990) Medium Chain Triglycerides, pp. 3-6. Philadelphia, PA: University of Pennsylvania Press.

Seydoux J, Giacobino JP \& Girardier L (1986) Effect of nafenopin, a peroxisome proliferator on energy metabolism in the rat as a function of acclimation temperature. Pflugers Arch 407, $377-381$.

Smith L (1955) Spectrophotometric assay of cytochrome c oxidase. Methods Biochem Anal 2, 427-434.

Srere PA (1969) Citrate synthase. Methods Enzymol 13, 3-5.

Surette ME, Whelan J, Broughton KS, et al. (1992) Evidence for mechanisms of the hypotriglyceridemic effect of $n-3$ polyunsaturated fatty acids. Biochim Biophys Acta 1126, 199-205.

Takeuchi H, Kubota F, Itakura M, et al. (2001) Effect of triacylglycerols containing medium- and long-chain fatty acids on body fat accumulation in rats. J Nutr Sci Vitaminol 47, 267-269.

Tsuji H, Kasai M, Takeuchi H, et al. (2001) Dietary medium-chain triacylglycerols suppress accumulation of body fat in a double-blind, controlled trial in healthy men and women. J Nutr 131, 2853-2869.

Viguerie-Bascand N, Saulier-Blache JS \& Dandie M (1999) Increase in uncoupling protein-2 mRNA expression by BRL49653 and bromopalmitate in human adipocytes. Biochem Biophys Res Commun 256, 138-141. 